\title{
Relative growth rates of three woody legumes: implications in the process of ecological invasion
}

\author{
João A. Crisóstomo, Helena Freitas and Susana Rodríguez-Echeverría
}

\begin{abstract}
Crisóstomo, J. A. et al. 2007. Relative growth rates of three woody legumes: implications in the process of ecological invasion. - Web Ecol. 7: 22-26.
\end{abstract}

\begin{abstract}
Acacia longifolia, an Australian leguminous tree, is one of the main invasive plant species in the coast of Portugal and a major threat to the native vegetation in the Reserva Natural das Dunas de São Jacinto. With the establishment of this exotic species, other native woody leguminous species such as Cytisus grandiflorus and Ulex europaeus have been displaced from their original areas. Several factors are involved in the process of biological invasion by exotic species. Plant physiology and development, characteristic of each species, can give certain advantages in the establishment and colonization of new areas. We tested if there are differences in the Relative Growth Rate (RGR) of the exotic and native species because this could be relevant in the first stages of the invasion process. Our results showed that $A$. longifolia was the species with lowest RGR. Therefore, other factors apart from RGR might explain the invasion of coastal dunes by this species. We propose that $A$. longifolia might be a better competitor than the two native legumes and that this process might be mediated by the interaction with soil organisms.
\end{abstract}

\section{J. A. Crisóstomo (biologoapolinario@gmail.com), H. Freitas and S. Rodriguez-Echeverría, Dept of Botany, Univ. of Coimbra, PT-3000 Coimbra, Portugal.}

Biological invasions have a great impact on ecosystem structure and functioning (Cronk and Fuller 1995) and are considered the second major threat to biodiversity (Vitousek 1997). Several hypotheses that examine either the characteristics of the invasive species, the invaded community, or the interactions between the invasive species and other organisms, have been proposed to explain the success of exotic species in colonizing new areas. Areas with high levels of disturbance, high resource availability or reduced diversity tend to be more easily colonized by exotic species (Shea and Chesson 2002). Exotic plant species could also be successful invaders because they lack the specific natural enemies which regulate their populations in native areas (Crawley 1997, Keane and Crawley 2002), or because they evolve an increased competitive ability in the new invaded areas (Blossey 1995). Plants with specific physiological or morphological attributes that make them good colonizers are likely to become invasive in new areas (Blumenthal 2005). Accordingly, a high relative growth rate (RGR) could be an important factor determining the success of exotic species and the displacement of native vegetation.

The invasion of $A$. longifolia, a species introduced in Portugal for dune stabilization, represents a major threat to the preservation of the local plant community in the Reserva Natural de São Jacinto and in many coastal areas in Portugal (Marchante 2003). The main areas affected by the invasion of this exotic species are in the secondary dune, therefore displacing other native woody species. Ulex europaeus and Cytisus grandiflorus are the most abundant native woody legumes in this habitat and they are highly affected by the expansion of $A$. longifolia. 
In order to elucidate the mechanisms that lead to the invasion success of this exotic species, we performed an experiment to estimate the RGR of A. longifolia, U. europaeus and C. grandiflorus. Since A. longifolia is displacing the other two native species, our hypothesis was that $A$. longifolia has a higher RGR than the two native species $U$. europaeus and C. grandiflorus.

\section{Material and methods}

\section{Seeds}

Seeds from the three plant species were randomly collected from plants in the Reserva Natural das Dunas de São Jacinto (Portugal) during summer 2005. Seed mass for each species was estimated by repeated measures of different groups of ten seeds in the case of A. longifolia and 50 seeds for the two other species. Seeds were dried at $40^{\circ} \mathrm{C}$ for $24 \mathrm{~h}$ and weighted in a laboratory weighing scale to estimate average seed mass.

\section{Plants}

Thirty seeds of each plant species were surface disinfected in $96 \%$ ethanol for $30 \mathrm{~s}$ and $4 \%$ bleach for two min, and then washed with autoclaved water previous to scarification. Seeds were scarified using a scalpel and placed in sterilized Petri dishes with autoclaved wet filter paper at $25^{\circ} \mathrm{C}$ for germination. After radicle emergence, seedlings were transplanted individually into one 1 pots, containing $700 \mathrm{~g}$ of sterilized quartz sand (eight $\mathrm{h}$ at $150^{\circ} \mathrm{C}$ for three times with intervals of eight h). Pots were watered with 100 $\mathrm{ml}$ of full strength Hoagland's solution on the first week, and then on every four days, with $30 \mathrm{ml}$ of distilled water alternated with $30 \mathrm{ml}$ of full strength Hoagland's solution. Plants were grown in a 700 EDTU Aralab Fitotron with a cycle of $16 \mathrm{~h}$ of light at $25^{\circ} \mathrm{C}$, and eight h of darkness at $18^{\circ} \mathrm{C}$.

\section{Harvest and data analyses}

Ten plants for each species were harvested at four, eight and twelve weeks. The fresh weight of shoot and root were

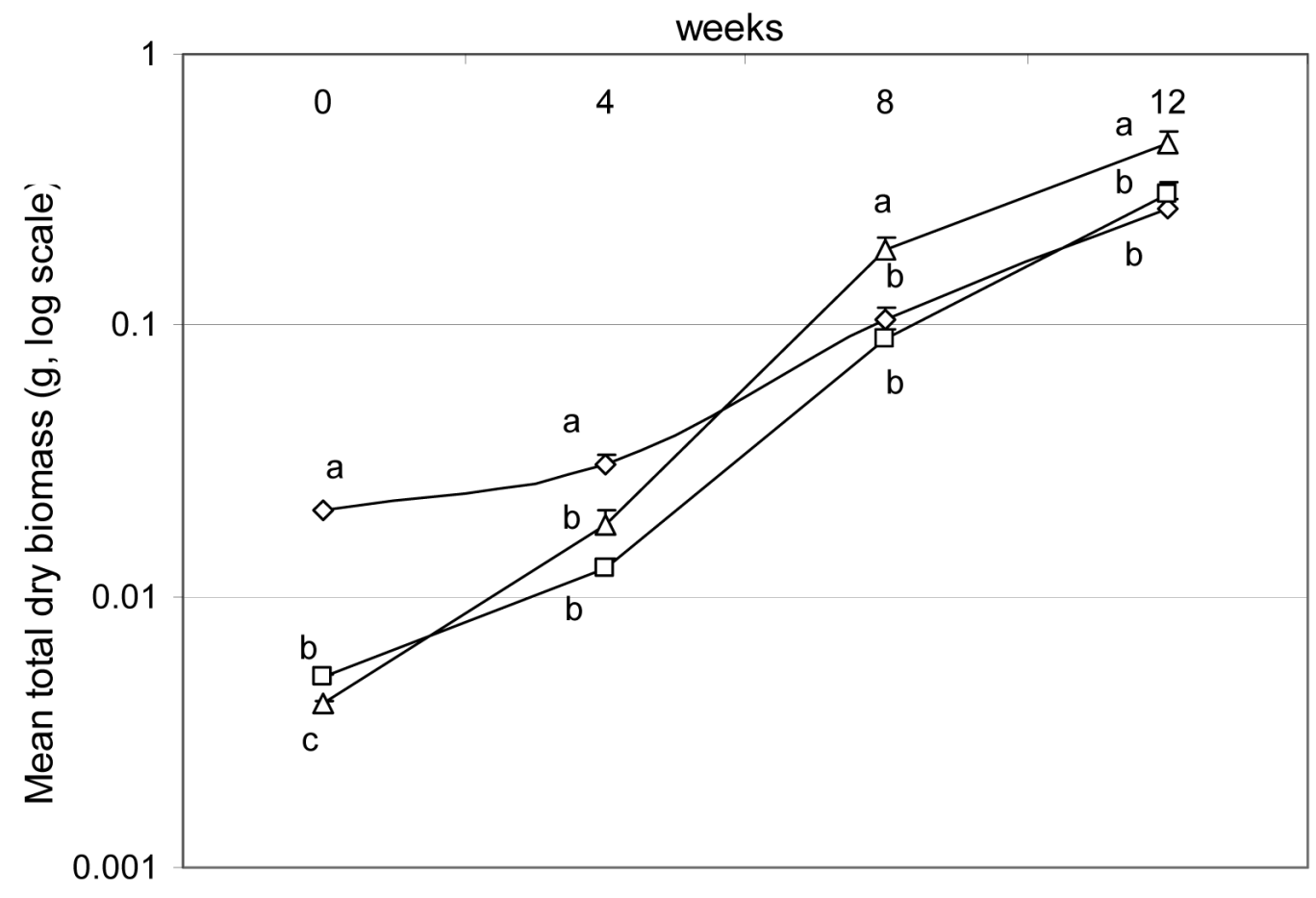

\section{$\checkmark$ A. longifolia $\neg-$ C. grandiflorus $\neg-U$. europaeus}

Fig. 1. Total dry biomass (mean \pm SE) for each harvest. The data for week 0 correspond to the seed weights. Different letters mean significant differences $(\mathrm{p}<0.05)$ between species in each harvest after one way ANOVA and Tukey's test. Note the log scale. 
recorded for each plant. Shoots and leaves were scanned with a HP scanjet 5370c at $300 \mathrm{dpi}$, and the leaf area was determined with the software ImageJ-Image Processing and Analysis in Java (available at <http://rsb.info.nih.gov/ ij/index.html $>$ ).

Plants were subsequently dried at $65^{\circ} \mathrm{C}$ for $48 \mathrm{~h}$ to measure the dry weight of shoot and root for each plant.

From these data, the following indices were calculated using Hunt's (2002) software:

RGR (mean Relative Growth Rate) - Rate of dry mass increase per dry mass unit $\left(\mathrm{d}^{-1}\right)$. RGR can be decomposed as ULR*LAR.

ULR (mean Unit Leaf Rate) - Rate of dry mass production per leaf area unit $\left(\mathrm{mg} \mathrm{cm}^{-2} \mathrm{~d}^{-1}\right)$.

LAR (mean Leaf Area Ratio) - Ratio between total leaf area per plant and total dry weight per plant $\left(\mathrm{cm}^{2} \mathrm{mg}^{-1}\right)$.

ANOVA and Tukey's test were used to compare biomass, RGR, ULR and LAR among the three species.

\section{Results and discussion}

Significant differences were found between the seed weight of the three species (Fig. 1). The biggest seeds were those of $A$. longifolia and the smallest the seeds produced by $U$. europaeus. This difference affected the early growth of the three plant species. After four weeks, the A. longifolia seed-
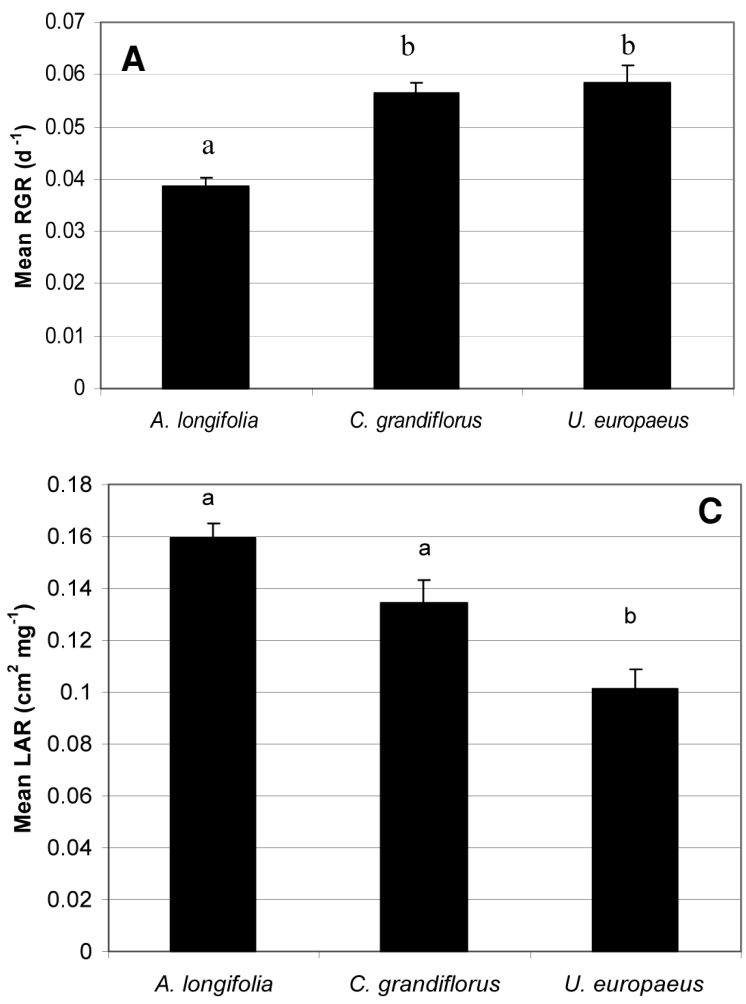

lings were significantly bigger than the seedlings of the other two species (Fig. 1). However, in the following harvests, at eight and 12 weeks, the highest values of biomass were found for the seedlings of $U$. europaeus. This value was significantly different from the biomass of the other two species.

We found significant differences in the RGR values between $A$. longifolia and the other two species over the entire studied period. The greatest value was found for $U$. europaeus (Fig. 2a). This species was also the one that showed the highest ULR (Fig. 2b), i.e. the highest growth rate per unit of leaf area. Since this is a measure of the plant physiological activity (Hunt et al. 1993), U. europaeus could be the species with the greatest photosynthetic efficiency, which is calculated as the ratio between the amount of total solar energy available and the chemical energy produced during photosynthesis. Since ULR also accounts for dark respiration rates, which were not measured in this work, we were not able to determine if the differences were due just to the photosynthetic efficiency or to a combination of both photosynthetic and respiration rates.

Significant differences in LAR values were also found between $U$. europaeus and the other two species. A. longifolia was the species with highest LAR values (Fig. 2c), i.e. the highest leaf area per unit of total dry mass of the three plant species. This might be an advantage in the coloniza-

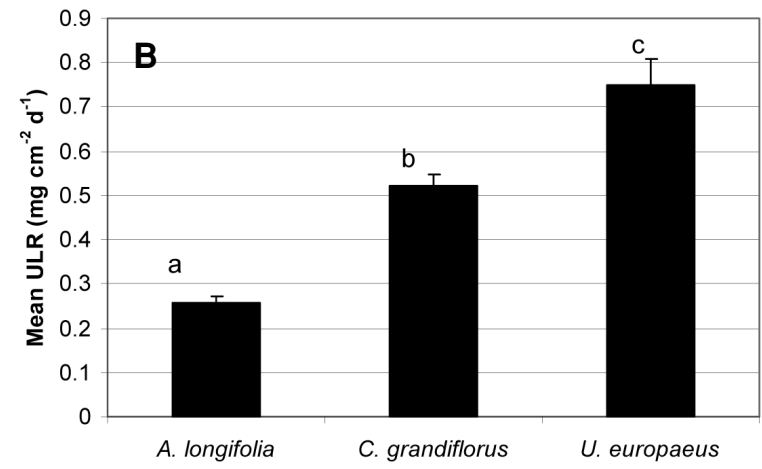

Fig. 2. Mean values $\pm S E$ of (A) RGR, (B) ULR, and (C) LAR of the three studied plant species over the entire growth period, from 4 to 12 weeks. Different letters mean significant differences $(\mathrm{p}<0.05)$ after one way ANOVA and Tukey test. 


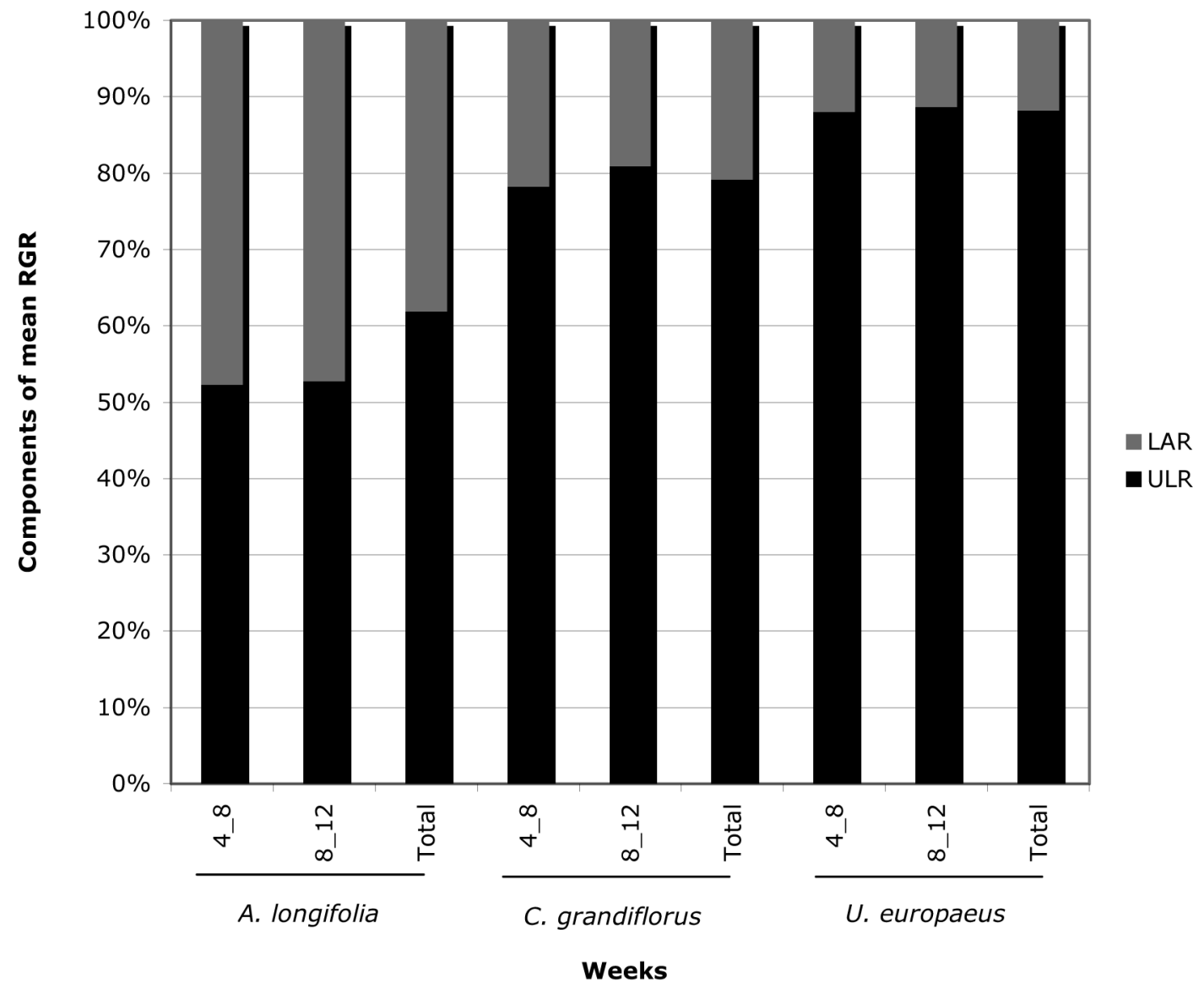

Fig. 3. Contribution (in percentage) of ULR and LAR to the value of RGR in the three plant species. Data refer to the growth period between four to eight weeks; eight to twelve weeks; and for the entire period (total).

tion process, because a higher leaf area can decrease the light available to seedlings of other species which are in the proximity of $A$. longifolia plants (Walters et al. 2000).

The analysis of the two components of the RGR hinted to ULR as the factor that most contributed to RGR (Fig. 3). This indicates that all species had a greater part of their RGR explained by the photosynthetic efficiency (Hunt et al. 1993). The relative contribution of ULR and LAR to RGR showed very little variation from one period to the other. Other previous studies have shown a temporal variation in the relative contribution of ULR to RGR because of the natural variation of the photoperiod (Antúnez 2001). In our experimental conditions, the photoperiod was constant so this could partially explain the even contribution of ULR and LAR to RGR through time.

The values of RGR were higher in the first monitored growth period (four-eight weeks) than in the second period (eight-twelve weeks) in all species. The greatest decrease in RGR was found for U. europaeus (Table 1). Al- though LAR had a greater decrease in all species from the first period to the second period, differences in RGR were also due to a decrease in ULR. This happens because ULR is the major component of RGR; therefore, little variation will have a significant effect in the values of RGR. These data highlight the rapid growth of $U$. europaeus between four and eight weeks.

To conclude, the species with the greatest RGR was $U$. europaeus followed by $C$. grandiflorus and then by A. longifolia. Thus, the high success of $A$. longifolia in the invasion process cannot be explained by the specific RGR of the three studied species. These results were obtained in controlled conditions with no nutrient shortage and the absence of other biotic interactions. The successful displacement of the native species in the field might be related to other factors such as differences in the competitive ability of each species (Blossey 1995) or interactions with other organisms that could change both the growth rate and the competitive outcome among the plant species (Klironomos 2002, Callaway 2004). 


\section{References}

Antúnez, I. 2001. Relative growth rate in phylogenetically related deciduous and evergreen woody species. - Oecologia 128: $172-180$.

Blossey, B. and Nötzold, R. 1995. Evolution of increased competitive ability in invasive non-indigenous plants: a hypothesis. - J. Ecol. 83: 887-889.

Blumenthal, D. 2005. Interrelated causes of plant invasion. Science 310: 243-244.

Callaway, R. M. et al. 2004. Soil biota and exotic plant invasion. - Nature 427: 731-733.

Crawley, M. J. 1997. Plant Ecology. - Blackwell Scientific.

Cronk, Q. B. and Fuller, J. L. 1995. Plant invaders. - Chapman $\&$ Hall.

Hunt, R. et al. 1993. Mean relative growth rate. - In: Hendry, G.A.F. and Grime, J. P. (ed.), Methods in Comparative Plant Ecology. Chapman \& Hall, pp. 98-102.

Hunt, R. et al. . 2002. A Modern Tool for Classical Plant Growth Analysis. - Ann. Bot.-London 90: 485-488.

Keane R. M and Crawley M. J. 2002. Exotic plant invasions and the enemy release hypothesis. - Trends Ecol. Evol. 14: 164170.

Klironomos, J. N. 2002. Feedback with soil biota contributes to plant rarity and invasiveness in communities. - Nature 417: 67-70.

Marchante, H. et al. 2003. Invasion of the Portuguese dune ecosystem by the exotic species Acacia longifolia (Andrews) wild: effects at the community level. - In: Child, L. E. et al. (ed.), Plant invasions: Ecological Threats and Management Solutions. Backhuys Publishers, pp. 5-85.

Shea, K. and Chesson, P. 2002. Community ecology theory as a framework for biological invasions. - Trends Ecol. Evol. 17: $170-176$.

Vitousek, P. M. et al. 1997. Introduced species: a significant component of human-caused global change. - New Zeal. J. Ecol. 21: $1-16$.

Walters, M. B. and Reich P. B. 2000. Seed size, nitrogen supply, and growth rate affect tree seedling survival in deep shade. Ecology 81: 1887-1901. 